\title{
DESIGN OF EXPERIMENT STUDY OF THE PARAMETERS THAT AFFECT PERFORMANCE OF THREE FLOW PLATE CONFIGURATIONS OF A PROTON EXCHANGE MEMBRANE FUEL CELL
}

\author{
J. G. Carton, A. G. Olabi* \\ Mechanical Engineering, Dublin City University, Dublin 9, Ireland
}

\begin{abstract}
Low temperature hydrogen fuel cells are electrochemical devices which offer a promising alternative to traditional power sources. Fuel cells produce electricity with a reaction of the fuel (hydrogen) and air. Fuel cells have the advantage of being clean; only producing water and heat as by products. The efficiency of a fuel cell varies depending on the type; SOFC with CHP for example, can have a system efficiency of up to $65 \%$.

What the Authors present here is a comparison between three different configurations of flow plates of a proton exchange membrane fuel cell, the manufacturer's serpentine flow plate and two new configurations; the maze flow plate and the parallel flow plate. A study of the input parameters affecting output responses of voltage, current, power and efficiency of a fuel cell is performed through experimentation. The results were taken from direct readings of the fuel cell and from polarisation curves produced. This information was then analysed through a design of experiment to investigate the effects of the changing parameters on different configurations of the fuel cell's flow plates.

The results indicate that, in relation to current and voltage response of the polarisation curve and the corresponding graphs produced from the DOE, the serpentine flow plate design is a much more effective design than the maze or parallel flow plate design. It was noted that the parallel flow plate performed reasonably well at higher pressures but over all statically the serpentine flow plate performed better.
\end{abstract}

KEYWORDS: PEM Fuel Cell, Design of Experiments, Flow Plate, Serpentine Flow Plate.

\section{INTRODUCTION}

PEM fuel cells, Figure 1, operate on the principle of an electrochemical reaction between hydrogen and oxygen with the aid of a catalyst (platinum) [1]. Hydrogen fuel is channelled through field flow plates to the anode on one side of the fuel cell while oxygen from the air is channelled to the cathode on the other side of the cell. At the anode, a platinum catalyst causes the hydrogen to split into positive hydrogen ions (protons) and negatively charged electrons. At the cathode, the electrons and positively charged hydrogen ions combine with oxygen to form water. Some water is expelled through the outlet; the rest may become trapped in the cell, which can lead to flooding within the cell [2]. The polymer electrolyte membrane allows only the positively charged ions to pass through it to the cathode. The negatively charged electrons must travel along an external circuit to the cathode, creating an electrical current.

The proton exchange membrane fuel cell has some advantages, it can produce high current densities and its operating temperature can be between $60^{\circ} \mathrm{C}$ and $80^{\circ} \mathrm{C}$, compared to other fuel cell types, such as the SOFC where the operating temperature is approximately $700^{\circ} \mathrm{C}[3]$. 


\subsection{Fuel Cell Testing}

A fuel cell was purchased with serpentine flow plates and an active area of $14.45 \mathrm{~cm}^{2}$ (Model: ECOFC-1 - H2Economy, Armenia). The cell was tested with the manufacturer's specifications, it was then disassembled, examined and modelled. Measuring these parameters and modelling the cell's flow plates was important as a bench mark. During this process it was evaluated that the cell was performing to the specifications set down by the manufacturer. From the knowledge gathered from the purchased fuel cell, new concepts and designs could be investigated [4,5]. Two new flow plates were designed, manufactured and tested. The new designs were named parallel flow plate design and maze flow plate design. All three flow plate configurations are shown in Figure 2. The new flow plates were tested and compared to the purchased serpentine flow plate to see differences or improvements in current voltage and power output at different parameters due to the new designs. This was achieved through design of experiment.

\section{DESIGN OF EXPERIMENTS}

This paper studies the different input parameters that affect the fuel cell performance and help determine which parameters contribute most and to determine the values of these parameters that lead to the best performance of a fuel cell.

A design of experiments (DOE) was required in order to successfully analyse the test parameters of the fuel cell. The DOE was used to create the experiment run order, and statistical analysis and to provide extensive graphs to highlight the relationship of the input parameters with the outgoing responses [6].

\subsection{Box-Behnken Design}

Box-Behnken designs are response surface designs, specially made to require only 3 levels, coded as $-1,0$, and +1 (see Table 1 ). They are formed by combining two-level factorial designs with incomplete block designs. This procedure creates designs with desirable statistical properties but, most importantly, with only a fraction of the experiments required for a three-level factorial. Because there are only three levels, the quadratic model is appropriate. Blocking options are also offered for most of these designs. The number of centre points was chosen to be 1 , to minimize the amount of experiments and because the centre point was not anticipated to be an important position. Many statistical programs can be used to setup and analyse a DOE; Stat-Ease or Mini tab are two common programs [7]. For this DOE, Stat-Ease is used because it dedicates itself to providing the best program for design and analysis of experiments and proved to be more than satisfactory for the type of study performed [8].

\subsection{Parameters}

The three parameters studied were the hydrogen flow rate, air flow rate and the inlet hydrogen pressure (see Table 1). Graphs are produced from the DOE software showing the responses of the parameters when the test fuel cell is examined. These results are shown in Figures $5-13$. The air pressure was set at 0.2 bar above the hydrogen pressure to accommodate the use of air, as stated by the manufacturer of the purchased fuel cell. The parameters were tested using three different flow plate designs, serpentine, maze and parallel shaped flow plates. Flow plate configuration and design can affect the fuel cell in many ways. Flow plates help distribute the gases over the reactant area of the MEA at various velocities and pressures. They can affect the polarisation performance of fuel cell and also aid the water management, particularly the water extraction from the cell [9]. Therefore a new improved design could produce a higher cell performance $[10,11]$. 


\subsection{Experimental Setup and Procedure}

The experimental setup is shown in Figure 3. The reactant gas, hydrogen, is stored in a compressed cylinder. A specialised hydrogen pressure regulator was purchased for safe and easy use and accurate control of the hydrogen gas flow (BOC series 8500 hydrogen pressure regulator). The gas then passes through volumetric flow meters (Voegtlin red-y series flow controller). The flow controllers are calibrated for the hydrogen gas and air. The flow controllers are controlled by the data acquisition (DAQ) software (Lab View). Both air and hydrogen gases were humidified as stated by the manufacturer of the MEA (Model: ECOFC1 - H2Economy, Armenia) using in house temperature controlled humidifiers. Saturator temperature was set equal to the fuel cell temperature to ensure full gas humidification. The humidified hydrogen and air streams were passed through the fuel cell until the temperature of the fuel cell steady stated. During testing humidification was kept constant; therefore not affecting the experiments.

The open circuit voltage and the fuel cell operating voltage are detected by the DAQ hardware and analysed through the software. The open circuit voltage reading is also double checked at the anode and cathode using a multimeter (Fluke 8808A digital multimeter). The fuel cell current is measured using a multimeter (Fluke 8808A digital multimeter) in series with the external load. A $12 \mathrm{Ohm}$ variable rheostat supplied the variable resistive load.

A hole was drilled at the centre of each back plate of the fuel cell to position the Ktype thermocouples as close to the centre of the fuel cell as possible. The thermocouples were placed into the fuel cell backing plate, against each flow plate, and the temperature values recorded through the DAQ system. The location of the thermocouples in the fuel cell indicated that the cell was operating between $55^{\circ} \mathrm{C}$ and $60{ }^{\circ} \mathrm{C}$ for all experiments. This was chosen to be a steady state region and fluctuations were minimised.

\section{$2.4 \quad$ Responses}

There were a number of important anticipated responses that were recorded. See Table 2. There were also various observations recorded during the experiments, these observations including temperature of the cell and the amount of water/condensation produced in the outflow tubing.

\subsection{Measuring the Responses}

In an electrical circuit Ohm's law states that voltage is proportional to current depending on the resistance as shown in equation 1.

$$
\mathrm{V}=\mathrm{I} \times \mathrm{R}
$$

where $\mathrm{V}$ is the voltage of the circuit, I the current flowing through the circuit and $\mathrm{R}$ is the resistance of the load in the circuit.

Fuel cell potential (V) is calculated differently than that of a normal circuit. The fuel cell's performance is summarised with the graph of its current and voltage characteristics. Voltage and current are measured from the fuel cell to plot the I-V (Current vs Voltage) or polarisation curve. An ideal fuel cell should produce any amount of current (as long as it is supplied with sufficient fuel) while maintaining a constant voltage determined by thermodynamics. However, due to losses, within the cell (including activation, ohmic and concentration losses) this is not the case for a practical fuel cell as shown in equation 2.

$$
\mathrm{V}=\mathrm{E}_{\text {thermo }}-\eta_{\text {act }}-\eta_{\text {ohmic }}-\eta_{\text {conc }}
$$

The open circuit voltage from the fuel cell is a good measure of electrical efficiency; the lower the open circuit voltage, the lower the electrical efficiency.

The power delivered by the fuel cell is given by the product of the measured current 
and the measured voltage at that current:

$$
\mathrm{P}=\mathrm{I} \times \mathrm{V}
$$

The power and current values are divided by the active area of the MEA, to make the results comparable to larger or smaller MEA's.

The experiments created a huge amount of data. Polarisation curves were drawn for all experiments. Figures 14, 15 and 16 show a sample of the polarisation curve results. For the DOE study the values at the intersection point (intercept) of both the power density and voltage against current density plots on each of the graphs for the individual experiments were recorded. The intercept is the point on the graph that gives a good compromise between high voltage and high power density. These values are added to the DOE software and analysed.

The voltage efficiency is recorded. The voltage efficiency is a measure of the maximum voltage, recorded at open circuit voltage, divided by the theoretical maximum voltage of $1.23 \mathrm{~V}[12]$.

$$
\varepsilon_{\text {voltage }}=\mathrm{V}_{\text {measure }} / \mathrm{V}_{\text {theoretical }}
$$

The fuel efficiency is a measure of the percentage of hydrogen used per unit time. Due to inefficiencies in the fuel cell or incorrect flow rates the fuel efficiency may be very low [13]. It can be calculated by comparing the input flow rate of hydrogen with the measured current from the cell using the formulae:

$$
\varepsilon_{\text {fuel }}=(\mathrm{I} / \mathrm{nF}) / v_{\text {fuel }}
$$

where $\mathrm{I}$ is the current produced during the experiment and $\mathrm{n} \times \mathrm{F}$, a constant $(2 \times 96485)$, remains the same for all experiments. The $v_{\text {fuel }}$ (rate at which fuel is supplied) value varies with the three different flow rate parameters. The $v_{\text {fuel }}$ for each of the experiments is calculated in the following manner; For example, the flow rate of $82.5 \mathrm{ml} / \mathrm{min}$ must be presented in $\mathrm{mol} / \mathrm{second}$

$$
82.5 \mathrm{ml} / \mathrm{min}=0.0013751 / \mathrm{sec} \text { or } 1.375 \times 10^{-6} \mathrm{~m}^{3} / \mathrm{s}
$$

As the unit mole is a mass unit the flow rate is calculated in mass per second, the flow rate is multiplied by hydrogen density which is 0.08988 grams per litre. Solving this shows that at this flow rate there is 0.000124 grams of hydrogen used per second. Two hydrogen molecules share a covalent bond so the molecular weight is half this value. Therefore the rate at which hydrogen fuel is supplied to the fuel cell is $6.179 \times 10^{-5} \mathrm{~mol} / \mathrm{sec}$.

The efficiency of the entire fuel cell can be calculated, where $\hat{\mathrm{H}}^{\circ}$ is the higher heating value of the fuel, by:

And also:

$$
\eta=\mathrm{IV} / v_{\text {fuel }} \hat{\mathrm{H}}^{\circ}
$$

$$
\eta=\varepsilon_{\text {voltage }} \times \varepsilon_{\text {fuel }}
$$

\subsection{Analysis of Data}

Before any of the results can be graphed, each response is statistically analysed using the design of experiments to verify the accuracy and account for errors in the experiments. The statistical software automatically lists the runs in randomized order, which protects against any lurking factors such as time, temperature, humidity etc.

There are a number of tools used to help analyse the results of each factor and suggest whether or not the data in the model needs to be transformed. Transformations include logs $\left(y^{\prime}=\ln (y+k)\right)$ and square roots $\left(y^{\prime}=\operatorname{sqrt}(y+k)\right)$. Transformation is usually required when the ratio of the max and the min value is greater than ten. By selecting the diagnostic tag and then selecting the box-cox option a transformation is recommended if it is required. Maximum voltage, maximum current, maximum voltage efficiency and maximum fuel 
efficiency were recommended for transformation. However these responses were not of great importance compared to the rest of the responses and were not transformed. Also transformations skewed the results so the results were left as original [14].

The plot in Figure 4 is the normality plot; this plot indicates whether or not the results are normally distributed. Ideally the normal plot of residuals will be a straight line, indicating no abnormalities. Residuals versus predicted response values are also viewed.

\section{$3 \quad$ RESULTS}

\subsection{Voltage}

According to the DOE maximum voltage is obtained by the fuel cell by using a high oxygen flow rate compared to the hydrogen flow rate. A flow rate of $15 \mathrm{ml} / \mathrm{min}$ of hydrogen and a flow rate of $150 \mathrm{ml} / \mathrm{min}$ of oxygen gave the maximum voltage for all pressures.

Using the serpentine flow plate the pressure between 0.7 bar (maximum $0.99 \mathrm{~V}$ ) and 1.7 bar (maximum $1.06 \mathrm{~V}$ ) only increased the voltage by a negligible amount. The maze flow plate had a maximum voltage of $0.99 \mathrm{~V}$ at maximum pressure and the parallel flow plate 0.97 $\mathrm{V}$ at maximum pressure. Figure 5 shows the serpentine flow plate and the maximum voltage achieved, the maze and parallel plates showed a similar graph.

Voltage efficiency was examined in relation to the maximum theoretical voltage that can be achieved at open circuit voltage. The serpentine flow plate achieved higher voltage throughout the tested flow rates and pressures, with the maximum voltage efficiency of just under $86 \%$ achieved at a low hydrogen flow rate $(15 \mathrm{ml} / \mathrm{min})$ and large oxygen flow rate $(150 \mathrm{ml} / \mathrm{min})$ at maximum pressure $(1.7 \mathrm{bar})$ (see Figure 6$)$. The parallel flow plate had a maximum voltage efficiency of only about $78 \%$ (see Figure 7 ) achieved a maximum pressure (1.7bar). The maximum voltage efficiency achieved for the maze flow plate was about $77 \%$ at $1.2 \mathrm{bar}$ pressure.

\subsection{Current}

Increasing the pressure of the gases did not play a major part in increasing maximum current achieved. The increased pressure only allowed the minimum current to increase from $0.6 \mathrm{~A}$ at low pressure $(0.7 \mathrm{bar})$ to $0.9 \mathrm{~A}$ at high pressure $(1.7 \mathrm{bar})$ on the serpentine plate for example.

High oxygen and hydrogen flow rates $(150 \mathrm{ml} / \mathrm{min})$ gave high current rates, maximum at about 3.1 A for the serpentine flow plate as shown in Figure 8 (a). However, at low hydrogen flow rate $(15 \mathrm{ml} / \mathrm{min})$ and at medium oxygen flow rate $(100 \mathrm{ml} / \mathrm{min})$ a reasonably high current for the serpentine flow plate is achieved. The current is marginally affected by changing hydrogen flow rates, this can show that some of the hydrogen is not being fully utilised by the cell at high hydrogen flow rates.

Using the maze flow plate with increased oxygen and hydrogen flow rates the current increased to a maximum of about $1.8 \mathrm{~A}$ as shown in Figure 8 (b). However at medium oxygen and hydrogen flow rates $(100 \mathrm{ml} / \mathrm{min})$ a high current was also achieved.

Similarly, high oxygen and hydrogen flow rates gave high current rates, maximum at about 2.6 A for the parallel flow plate (see Figure 8 (c)). At medium oxygen and hydrogen flow rates and medium pressure the current was maximum at $2 \mathrm{~A}$.

\subsection{Maximum power at intercept}

The intercept is the point on the graph that gives a good compromise between high voltage and high power density. From the DOE study it was found that with increased hydrogen and oxygen flow rates the power increased. A maximum power of just under 0.44 
$\mathrm{W}$ is achieved for the serpentine flow plate at medium to high pressures (1.2 bar to 1.7 bar) (see Figure 9).

A maximum power of about $0.24 \mathrm{~W}$ is achieved for the maze flow plate at medium pressure (1.2 bar). No major increase was seen at the high pressure (1.7 bar).

A maximum power of about $0.41 \mathrm{~W}$ is achieved for the parallel flow plate at medium pressure (1.2 bar) as shown in Figure 10 (a).Interestingly the parallel flow plate did show high maximum power results up to $0.51 \mathrm{~W}$ at the maximum pressure $(1.7 \mathrm{bar})$ as shown in Figure 10 (b).

\subsection{Maximum fuel efficiency}

A quadratic plot is used as a better indication of what is happening to the fuel cell. As the hydrogen flow rate decreases, using the serpentine flow plate, at lower pressures $(0.7$ bar) the fuel efficiency increases. As the oxygen flow rate increase from $15 \mathrm{ml} / \mathrm{min}$ the fuel efficiency increases. However a maximum flow rate of $120 \mathrm{ml} / \mathrm{min}$ is reached when the fuel efficiency begins to decrease again (see Figure 11). A maximum fuel efficiency of about 30 $\%$ can be achieved at minimum pressure $(0.7$ bar $)$ and minimum hydrogen flow rate $(15 \mathrm{ml} / \mathrm{min})$ and oxygen flow rate at $120 \mathrm{ml} / \mathrm{min}$.

The maze flow plate had a lower fuel efficiency of just less than $17 \%$ at minimum pressure $(0.7 \mathrm{bar})$ and minimum hydrogen flow rate $(15 \mathrm{ml} / \mathrm{min})$ with the oxygen flow rate at $102 \mathrm{ml} / \mathrm{min}$ (see Figure 12).

The maximum fuel efficiency of about $25 \%$ can be achieved using the parallel flow plate at minimum pressure $(0.7 \mathrm{bar})$ and minimum hydrogen flow rate $(15 \mathrm{ml} / \mathrm{min})$ with the oxygen flow rate at $80 \mathrm{ml} / \mathrm{min}$ (see Figure 13 ).

\section{DISCUSSION}

Industrial countries have been trying to develop new energy technologies in both national and international programmes to meet the challenges of climate change since the 1970's [15]. Fuel cell technology is one of the developing technologies. There are many papers in literature that detail much work in the modelling of PEM fuel cells and many examine the internal heat and mass transfer of the cell as this information cannot be easily obtained experimentally [16].

However, gas and water management is the key to achieving good performance from a proton exchange membrane fuel cell stack [9]. The field flow plates have to meet the conflicting requirements of providing good electrical contact and easy passage and even distribution of the gases concerned, hydrogen to the surface of the anode and air or oxygen to the surface of the cathode.

A study of the input parameters affecting output responses is performed, through experimentation of a single cell, and a comparison between three different configurations of flow plates of a proton exchange membrane fuel cell, the manufacturer's serpentine flow plate and two new configurations; the maze flow plate and the parallel flow plate, Figure 2 in section 1, was presented in this paper. The design of experiment procedure is used to analyse the effects of the changing parameters on different configurations of the fuel cell's flow plates and predict optimum parameters for the best flow plate design.

\subsection{DOE - Voltage, current and power}

An ideal fuel cell will have a constant voltage but due to the losses, this is not the case for a practical cell. The fuel cell's performance is summarised with the polarisation curve (I$\mathrm{V}$ graph) of its current and voltage characteristics (see Figure 14, 15 and 16). The characteristics of the voltage/current density graph are a result of four major losses: 
- Activation

- Ohmic

- Mass Transport

- Fuel Cross Over and Internal Current Losses

Activation losses, fuel cross over and internal current losses would have been consistent from one experiment to the next; the same flow plate material was used in all the flow plates, the same MEA was used for all experiments and the operating temperature was kept constant. Ohmic losses due to resistance to flow of electrons could have been marginally different from one flow plate configuration to the next, due to the amount of surface area in contact with the MEA. Mass transport and concentration losses were noticed in some experiments. When the hydrogen flow rate was low compared to the air or oxygen flow rate the voltage was maximised.

Maximum open circuit voltage is obtained by the fuel cell by using a high oxygen flow rate compared to the hydrogen flow rate. A flow rate of $15 \mathrm{ml} / \mathrm{min}$ of hydrogen and a flow rate of $150 \mathrm{ml} / \mathrm{min}$ of oxygen gave the maximum voltage for all pressures, maximum at about $1.06 \mathrm{~V}$ from the DOE analysis. Using Eq. (3) calculates that the best voltage efficiency of about $86 \%$ is achieved by the serpentine flow plate also (see Figure 6).

High oxygen and hydrogen flow rates $(150 \mathrm{ml} / \mathrm{min})$ gave high current rates, maximum of $3.1 \mathrm{~A}$ for the serpentine flow plate. However, at low hydrogen flow rates $(15 \mathrm{ml} / \mathrm{min})$ and at medium oxygen flow rates $(100 \mathrm{ml} / \mathrm{min})$ a high current for the serpentine flow plate is achieved as shown in Figure 8 (a). The current is marginally affected by changing hydrogen flow rates, this can show that some of the hydrogen is not being fully utilised by the cell at high hydrogen flow rates. It was noted that pressure increase did not affect the current produced as long as sufficient flow rates were maintained.

The intersection point or intercept of the I-V curve of the fuel cell is the point on the graph that gives a good compromise between high voltage and high power density. From the DOE study it was found that with increased hydrogen and oxygen flow rates the power increased. A maximum power of about $0.44 \mathrm{~W}$ is achieved for the serpentine flow plate at medium to high pressures (see Figure 9). It was noted that at minimum pressure, minimum hydrogen flow rate and maximum oxygen flow rate a maximum voltage of about $0.97 \mathrm{~V}$ can be achieved and a maximum current at low resistance $(0.01 \Omega)$ of $2.90 \mathrm{~A}$ can be obtained. The fuel efficiency was about $30 \%$ but a peak of $37 \%$ was seen in the fuel efficiency plots. This peak was inconsistent with the results and the predictions of the DOE and so was discarded.

\subsection{Polarisation graphs}

Polarisation graphs alone can be used to help deduce the effectiveness of a fuel cell in relation to current and power density and voltage. Readings can distinguish slight differences in the fuel cells results. These graphs were constructed for every experiment.

The DOE study is an approximate indication of the performance of the fuel cell. It indicates what parameters work best together and concludes over all that the serpentine flow plate has shown to be the most effective flow plate. However it was noted that the serpentine flow plate performed lower than the parallel flow plate in certain cases. When all the results were viewed it was noticed that at a hydrogen flow rate of $82.5 \mathrm{ml} / \mathrm{min}$ and an air flow rate of $150 \mathrm{ml} / \mathrm{min}$ some interesting results came to light.

At a low pressure of 0.7 bar the serpentine flow plate performs best in relation to power density and current density (see Figure 14). The parallel flow plate closely matches the serpentine flow plate with a slightly lower current density but a higher open circuit voltage. These results correlate with the DOE analysis. 
The maze flow plate shows very poor results, performing best overall at 1.2 bar (see Figure 15) but very poorly at the higher pressure of 1.7 bar. The maze flow plate voltage drops very quickly with very no levelling off. This suggests that there are huge losses as the current increases. These results correlate with the DOE analysis.

However the parallel flow plate, at 1.2 bar, (see Figure 15) performs marginally better than the serpentine flow plate in relation to current density and power density. Further analysis of the polarisation graph shows, at 1.7 bar pressure, (see Figure 16) the parallel flow plate performs better than the serpentine flow plate. The current density being almost 0.005 $\mathrm{W} / \mathrm{cm}^{2}$ better. The parallel flow plate voltage drops quickly to under $0.8 \mathrm{~V}$ and tapers off as shown in Figure 16.

The DOE analysis does show predicted results and the best parameters that suit each flow plate. The DOE was performed to utilise this fact. However by examining the polarisation curves in detail and comparing it to anomalies seen in graphs of the DOE new conclusions may be drawn.

\subsection{Flow plate effectiveness}

The maze flow plate did not perform well and gave the lowest current $(1.63 \mathrm{~A})$ and efficiency results (maximum at 17\%) and in general gave low results in all experimental runs. The reason for poor results with the maze flow plate design could be due to the short period of time that the gas was in the cell to react. The open design of the flow plate as shown in Figure 2 may have reduced the ability of the gas to contact the MEA effectively. In addition the open central structure may have allowed for a large pressure drop and a direct flow from the inlet to the outlet resulting in minimal amounts of hydrogen and oxygen to react with the entire surface area of the cell. Flooding of the cathode can slow the oxygen reaction and so reduce current produced. However because of the design of the maze flow plate water flooding was not seen as the main contribution to the poor performance. The voltage however at the optimised point was quite high at $0.9871 \mathrm{~V}$. This high voltage could be attributed to the central design of the maze plate. This region has more surface area in contact with the MEA and therefore ohmic resistance within the cell could have been reduced. Overall the maze flow plate design could be re-evaluated but due to such a poor power and current response, this type of design is not as effective as the other flow plates tested.

The parallel flow plate performed almost as well as the serpentine flow plate, which overall performed the best. At maximum pressure $(1.7$ bar $)$, minimum hydrogen flow rate $(15 \mathrm{ml} / \mathrm{min})$ and maximum oxygen flow rate $(150 \mathrm{ml} / \mathrm{min})$ a maximum voltage of about $0.9658 \mathrm{~V}$ as compared to $0.9786 \mathrm{~V}$ with the serpentine flow plate can be achieved and a maximum current at low resistance of $2.40 \mathrm{~A}$ as compared to $2.90 \mathrm{~A}$ with the serpentine flow plate can be obtained. With these parameters the fuel efficiency can be as high as $25 \%$ for the parallel flow plate. The parallel flow plate did perform best at high pressure $(1.7 \mathrm{bar})$. At a hydrogen flow rate of $82.5 \mathrm{ml} / \mathrm{min}$ and an oxygen flow rate of $150 \mathrm{ml} / \mathrm{min}$ the parallel outperformed the serpentine flow plate. These parameters seem to be suited to the specific design. Water accumulation in the parallel flow plate channels at low pressures could have reduced performance by blocking the flow of oxygen to some areas of the MEA. At higher pressures the blockages may have been dislodged and better results were recorded. A maximum power of about $0.43 \mathrm{~W}$ is achieved for the parallel flow plate at medium to high pressures. However the parallel flow plate had a peak of $0.51 \mathrm{~W}$ of power at high pressures during the experiments see Figure 10 (b). This peak was inconsistent with the predictions of the DOE but it does suggest that this flow plate design if modified or if operated at slightly higher temperatures to reduce liquid water within the channels could yield better results.

The results indicate that in relation to current and voltage response of the polarisation curve and the corresponding graphs produced from the DOE, that the serpentine flow plate 
design is a much more effective design than the maze or parallel flow plate design. It was noted that the parallel flow plate performed reasonably well at higher pressures but over all statically the serpentine flow plate performed better.

\section{CONCLUSION}

To optimise a fuel cell many parameters have to be taken into account. The design of the cell and also the working conditions play a major part in how well the cell can perform. To account for the variables a DOE was performed to record the inputs and analyse the outputs. The DOE provide solutions as to which parameter settings provided the best results for each of the responses. By studying the analysis of variance it can be concluded that the experimental results are satisfactory. The DOE allows for any odd results to be highlighted, if any results are highlighted, the input results can be checked to ensure they were entered correctly and the experiments were carried out satisfactorily.

The purchased fuel cell is bench marked so the cells performance could be easily compared when using different flow plates and varying the input parameters. The purchased fuel cell performed lower than other PEM fuel cells in literature but this did not affect the study as a comparison is performed to investigate the most effective flow plate using optimum input parameters. The results should be scalable to larger and more efficient fuel cells with different MEA or GDL designs or different platinum loading.

Pressure does not play a major role in the results of this single fuel cell. The main factor that influenced voltage was higher oxygen flow rates. Unsurprisingly the main factor in fuel efficiency is the hydrogen flow rate. Each of the experiments results run at the lowest hydrogen flow rate produced the best efficiency, however between both medium $(82.5 \mathrm{ml} / \mathrm{min})$ and high $(150 \mathrm{ml} / \mathrm{min})$ flow rate values other factors influenced fuel efficiency, mainly the flow plate design.

Overall the results indicate that in relation to current and voltage response of the polarisation curve and the corresponding graphs produced from the DOE, that the serpentine flow plate design is a much more effective design than the maze or parallel flow plate design. It was noted that the parallel flow plate performed reasonably well at higher pressures but over all statically the serpentine flow plate performed better.

The DOE was used as a guide to predict the best parameters for the cell with the serpentine flow plate. Using the serpentine flow plate at a low hydrogen flow rate of $15 \mathrm{ml} / \mathrm{min}$ and high air flow rate of $150 \mathrm{ml} / \mathrm{min}$ with a hydrogen pressure of 0.7 bar and an air pressure of 0.9 bar gave the best overall results; $0.97 \mathrm{~V}$ maximum voltage and $2.9 \mathrm{~A}$ maximum current. With the cell operating at $0.60 \mathrm{~V}$ would give a current of $0.60 \mathrm{~A}$ and a power density of $0.025 \mathrm{~A} / \mathrm{cm}^{2}$ with a hydrogen fuel efficiency of $30 \%$ and using equation 7 in section 2.5 an overall cell efficiency of about $15 \%$.

Future work could include changing the humidity of the gases or the operating temperature of the cell, since these may have a large effect using different flow plate designs into the performance of the fuel cell and water management. 


\section{REFERENCES}

[1]Peavey MA. Fuel From Water: Energy Independence with Hydrogen. 11th ed. Louisville KY: Merit Inc; 2003.

[2]Cook B. Introduction to fuel cells and hydrogen technology. Eng.Sci.Educ.J. 2002 $12 ; 11(6): 205-16$

[3]Supramaniam S. Fuel Cells: From Fundamentals to Applications New York: Springer Science \& business Media; 2006.

[4]Xiao-Dong Wang, Yuan-Yuan Duan, Wei-Mon Yan, Xiao-Feng Peng. Local transport phenomena and cell performance of PEM fuel cells with various serpentine flow field designs. J.Power Sources 2008 01/03;175(1):397-407.

[5]Mustata R, Valino L, Barreras F, Gil MI, Lozano A. Study of the distribution of air flow in a proton exchange membrane fuel cell stack. J.Power Sources 2009;192(1):185-189.

[6]Wei-Lung $\mathrm{Yu}$, Sheng-Ju $\mathrm{Wu}$, Sheau-Wen Shiah. Parametric analysis of the proton exchange membrane fuel cell performance using design of experiments. Int $\mathrm{J}$ Hydrogen Energy 2008 05;33(9):2311-22.

[7]Design-Expert software program. 2008. See Also: http://www.statease.com/expert.html.

[8]Grant F. Planning for the unexpected recent releases for design of experiment software. 2008. See Also: http://www.scientific-computing.com/features/feature.php?feature id=21.

[9]Hassan NSM, Daud WRW, Sopian K, Sahari J. Water management in a single cell proton exchange membrane fuel cells with a serpentine flow field. J.Power Sources 2009;193(1):249-257.

[10]Zhan Z, Xiao J, Zhang Y, Pan M, Yuan R. Gas diffusion through differently structured gas diffusion layers of PEM fuel cells. Int J Hydrogen Energy 2007 12;32(17):4443-51.

[11]Reddy RG. Fuel cell and hydrogen economy. Journal of Materials Engineering and Performance 2006 08;15(4):474-83.

[12]Barbir F. PEM Fuel Cells: Theory and Practice. USA: Elsevier Acadamic Press; 2005.

[13]O'Hayre R, Cha S, Colella W, Prinz FB. Fuel Cell Fundamentals. USA: John Wiley and Sons; 2006.

[14]Montgomery DC. Design and Analysis of Experiments. 5th ed. New York: John Wiley and Sons; 2001.

[15]Neef H-. International overview of hydrogen and fuel cell research. Energy 2009 $03 ; 34(3): 327-33$.

[16]Siegel C. Review of computational heat and mass transfer modeling in polymerelectrolyte-membrane (PEM) fuel cells. Energy 2008;33(9):1331-1352. 


\begin{tabular}{|c|c|c|}
\hline PEMFC & $=$ & Proton exchange membrane fuel cell \\
\hline CHP & $=$ & Combined heat and power \\
\hline GDL & $=$ & Gas diffusion layer \\
\hline PEM & $=$ & Proton exchange membrane \\
\hline DOE & $=$ & Design of experiment \\
\hline SOFC & $=$ & Solid oxide fuel cell \\
\hline MEA & $=$ & Membrane electrode assembly \\
\hline DAQ & $=$ & Data acquisition \\
\hline GFE & $=$ & Gibbs free energy \\
\hline $\mathrm{I}-\mathrm{V}$ & $=$ & Current Vs Voltage \\
\hline V & $=$ & Voltage \\
\hline I & $=$ & Current \\
\hline $\mathrm{R}$ & $=$ & Resistance \\
\hline $\mathrm{P}$ & $=$ & Power \\
\hline$\varepsilon$ & $=$ & Efficiency \\
\hline e & $=$ & Electronic charge \\
\hline $\mathrm{F}$ & $=$ & Faradays constant \\
\hline $\mathrm{n}$ & $=$ & $\begin{array}{c}\text { Number of moles of electrons } \\
\text { transferred }\end{array}$ \\
\hline$\eta$ & $=$ & Total efficiency of the fuel cell \\
\hline$\hat{\mathrm{H}}^{\circ}$ & $=$ & Higher heating value of the fuel \\
\hline$v$ & $=$ & Rate at which fuel is supplied \\
\hline $\mathrm{E}_{\text {thermo }}$ & $=$ & Thermodynamic Fuel cell Voltage \\
\hline$\eta_{\text {act }}$ & $=$ & Activation losses \\
\hline$\eta_{\text {ohmic }}$ & $=$ & Ohmic losses \\
\hline$\eta_{\text {conc }}$ & $=$ & Concentration losses \\
\hline
\end{tabular}




\section{List of Tables:}

Table 1 Fuel cell parameters

Table 2 Responses investigated

\begin{tabular}{|l|c|c|c|}
\hline DOE Level & $\mathbf{- 1}$ & $\mathbf{0}$ & $\mathbf{+ 1}$ \\
\hline Parameter Level & Low & Medium & High \\
\hline Hydrogen Pressure & $0.7 \mathrm{bar}$ & $1.2 \mathrm{bar}$ & $1.7 \mathrm{bar}$ \\
\hline Air/Oxygen Pressure & $0.9 \mathrm{bar}$ & $1.4 \mathrm{bar}$ & $1.9 \mathrm{bar}$ \\
\hline Hydrogen Volumetric Flow Rate & $15 \mathrm{ml} / \mathrm{min}$ & $82.5 \mathrm{ml} / \mathrm{min}$ & $150 \mathrm{ml} / \mathrm{min}$ \\
\hline Oxygen Volumetric Flow Rate & $15 \mathrm{ml} / \mathrm{min}$ & $82.5 \mathrm{ml} / \mathrm{min}$ & $150 \mathrm{ml} / \mathrm{min}$ \\
\hline
\end{tabular}

Table 1Fuel Cell Parameters

\begin{tabular}{|c|c|}
\hline Maximum Voltage & V \\
\hline Maximum Current & A \\
\hline Current at intercept of I-V graph & A \\
\hline Voltage at intercept of I-V graph & V \\
\hline Power at intercept of I-V graph & W \\
\hline Power Density at intercept of I-V graph & W/cm2 \\
\hline Maximum Power Density & W/cm2 \\
\hline Maximum Voltage Efficiency & $\%$ \\
\hline Hydrogen Fuel Efficiency & $\%$ \\
\hline
\end{tabular}

Table 2 Responses Investigated 


\section{List of Figures:}

Figure 1 Purchased PEM fuel cell exploded view

Figure 2 Serpentine flow plate, parallel flow plate and maze flow plate designs Figure 3 Experimental setup

Figure 4 Normality plot

Figure 5 Serpentine flow plate maximum voltage at maximum pressure

Figure 6 Serpentine flow plate maximum voltage efficiency at maximum pressure

Figure 7 Parallel flow plate maximum voltage efficiency at maximum pressure

Figure 8 Maximum current achieved at maximum pressure for (a) Serpentine flow plate (b) Maze flow

plate (c) Parallel flow plate

Figure 9 Serpentine flow plate power at intercept on I-V curve at medium pressure

Figure 10 Parallel flow plate power at intercept on I-V curve at; medium pressure (a) maximum pressure

(b) (Red points indicate experimental values above predicted DOE values)

Figure 11 Serpentine flow plate fuel efficiency at medium pressure

Figure 12 Maze flow plate fuel efficiency at medium pressure

Figure 13 Parallel flow plate fuel efficiency at medium pressure

Figure 14 Polarisation curves for flow plates (Pressure $0.7 \mathrm{bar} \mathrm{H} 2$ flow rate $82.5 \mathrm{ml} / \mathrm{min} 02$ flow rate $150 \mathrm{ml} / \mathrm{min}$ )

Figure 15 Polarisation curves for flow plates (Pressure 1.2bar $\mathrm{H} 2$ flow rate $82.5 \mathrm{ml} / \mathrm{min} 02$ flow rate $150 \mathrm{ml} / \mathrm{min})$

Figure 16 Polarisation curves for flow plates (Pressure 1.7bar $\mathrm{H} 2$ flow rate $82.5 \mathrm{ml} / \mathrm{min} 02$ flow rate $150 \mathrm{ml} / \mathrm{min}$ )

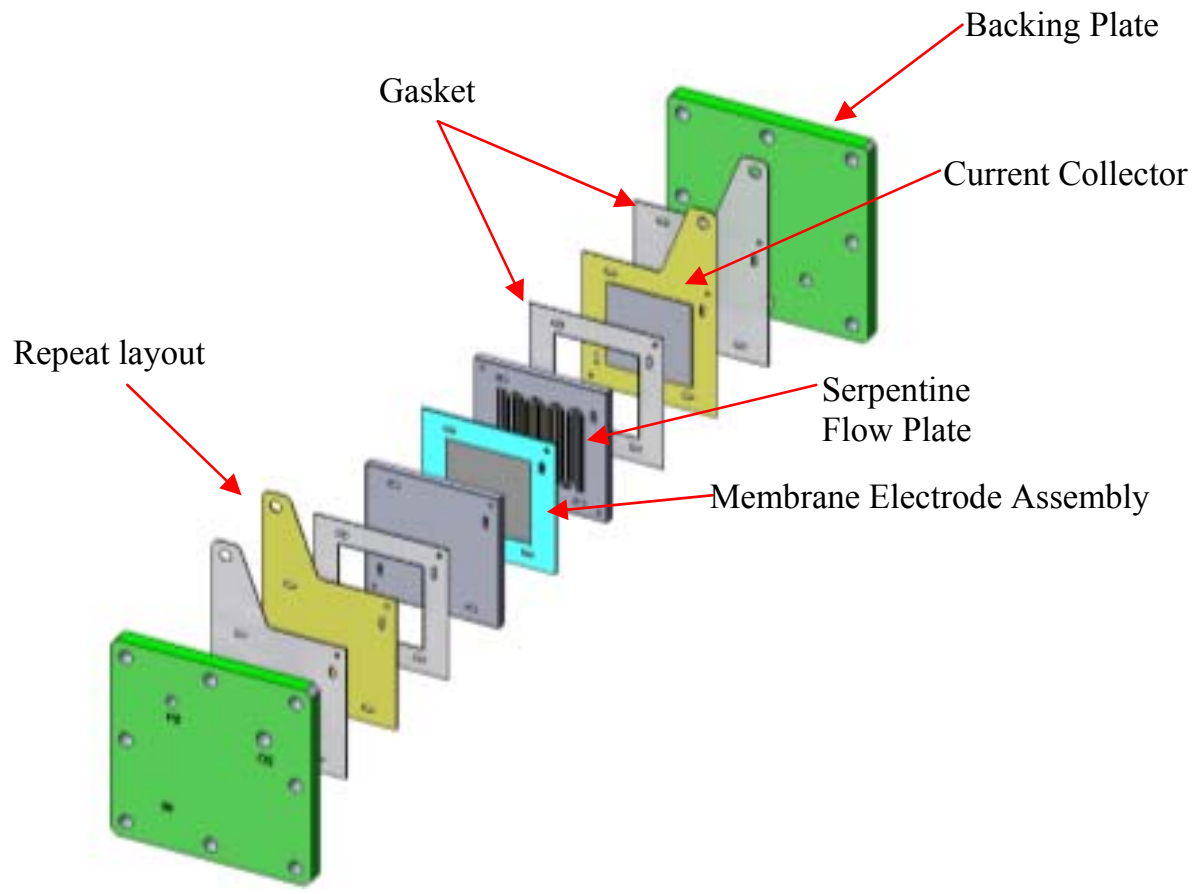

Figure 1 Purchased PEM fuel cell exploded view 

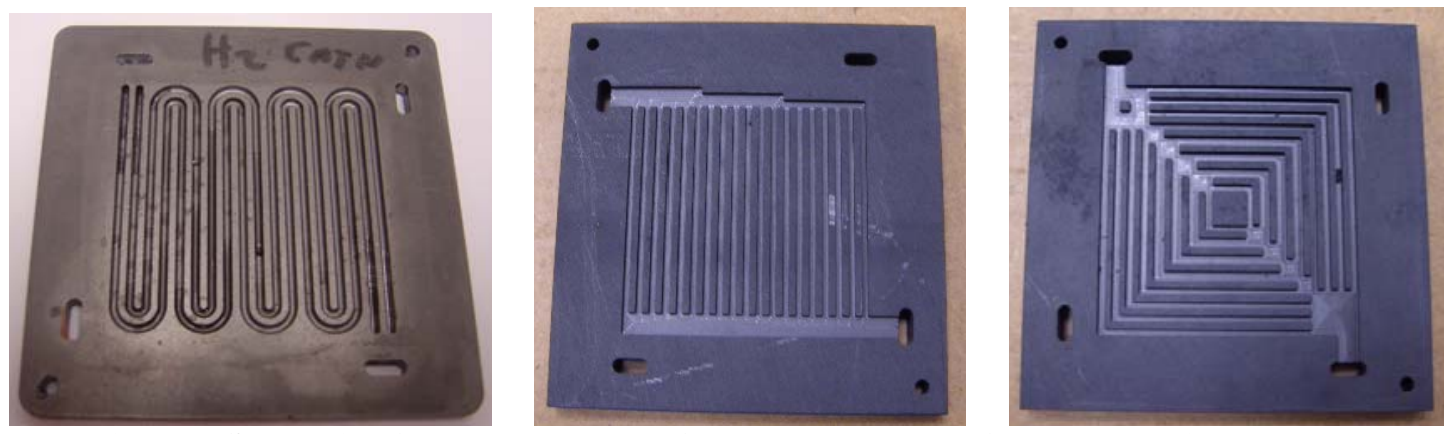

Figure 2 Serpentine flow plate, parallel flow plate and maze flow plate designs

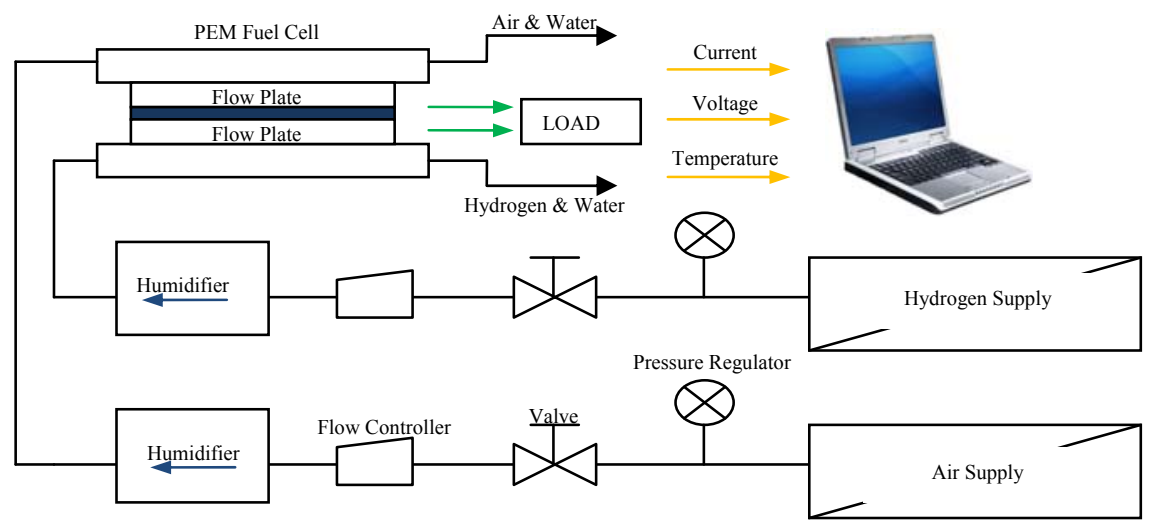

Figure 3 Experimental setup
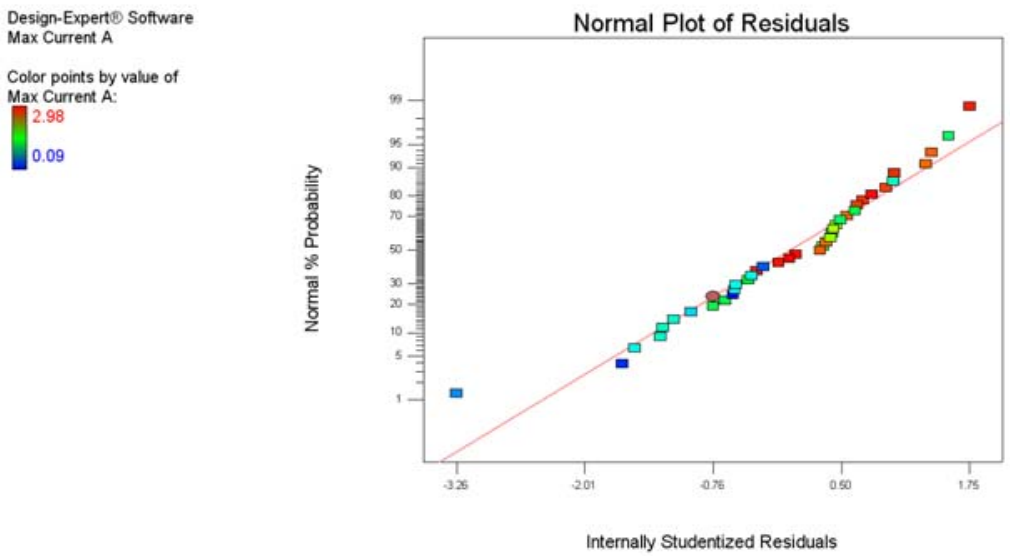

Figure 4 Normality plot 


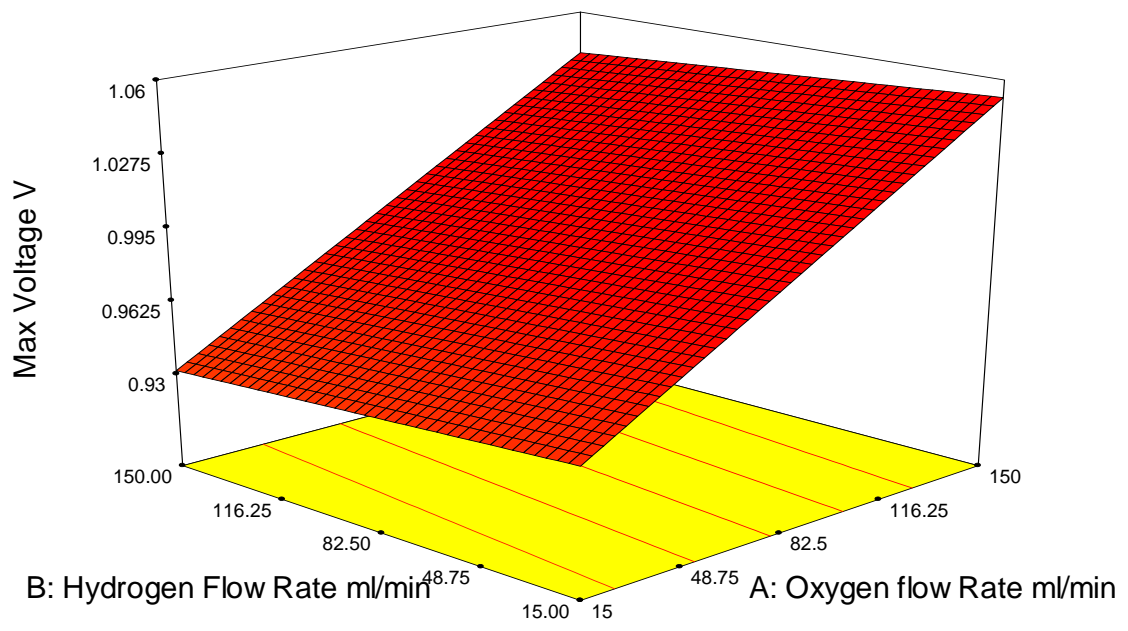

Figure 5 Serpentine flow plate maximum voltage at maximum pressure

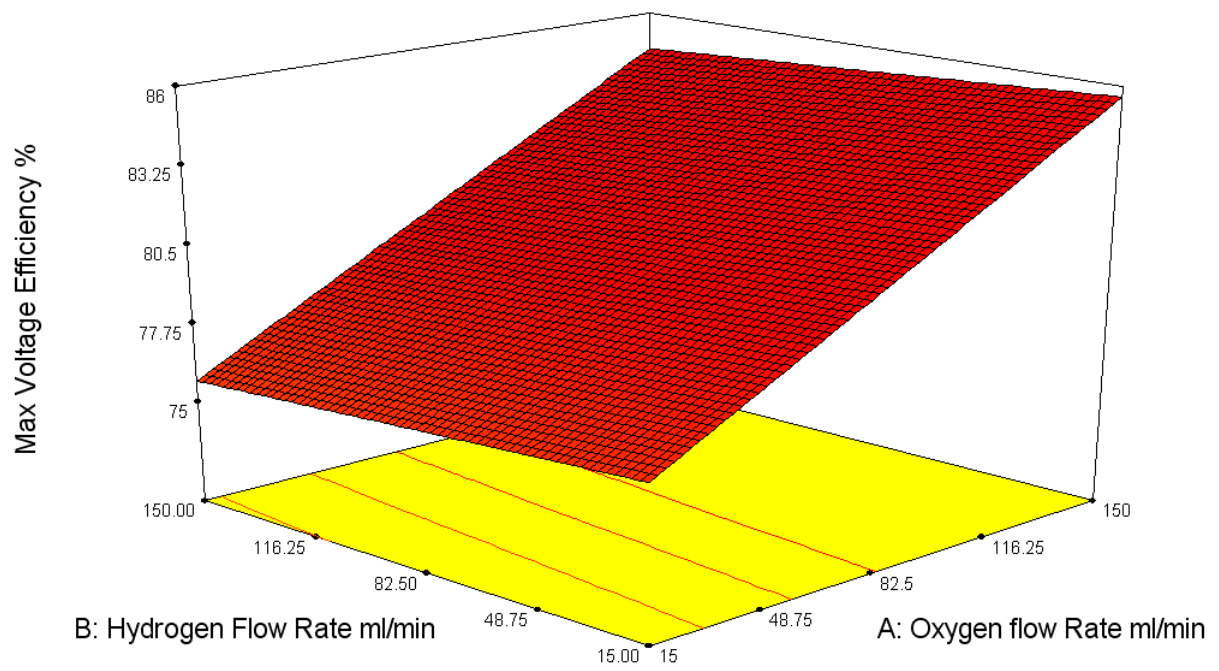

Figure 6 Serpentine flow plate maximum voltage efficiency at maximum pressure

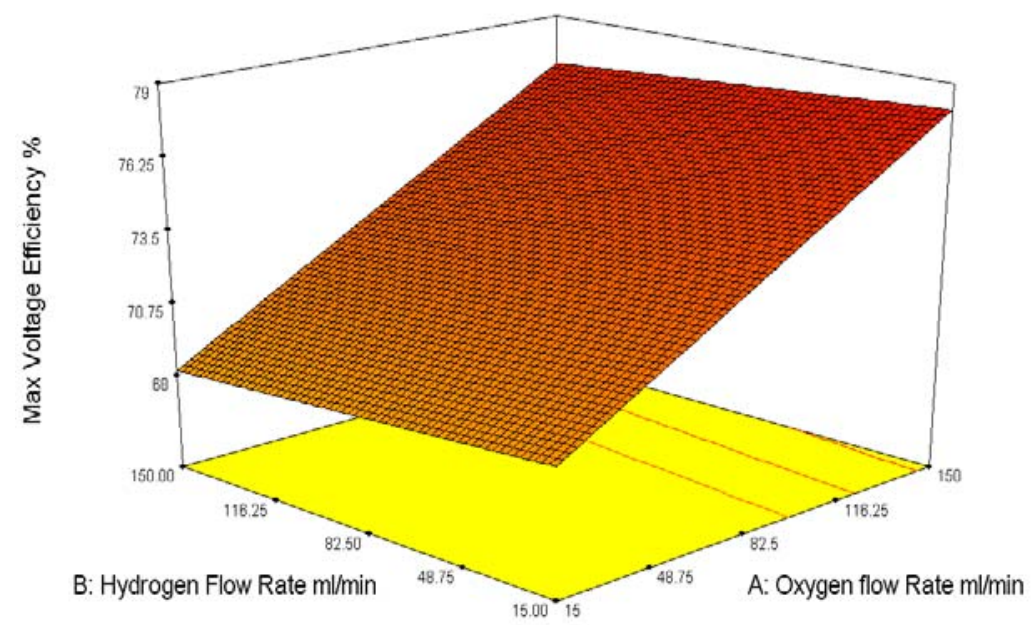

Figure 7 Parallel flow plate maximum voltage efficiency at maximum pressure 
(a)

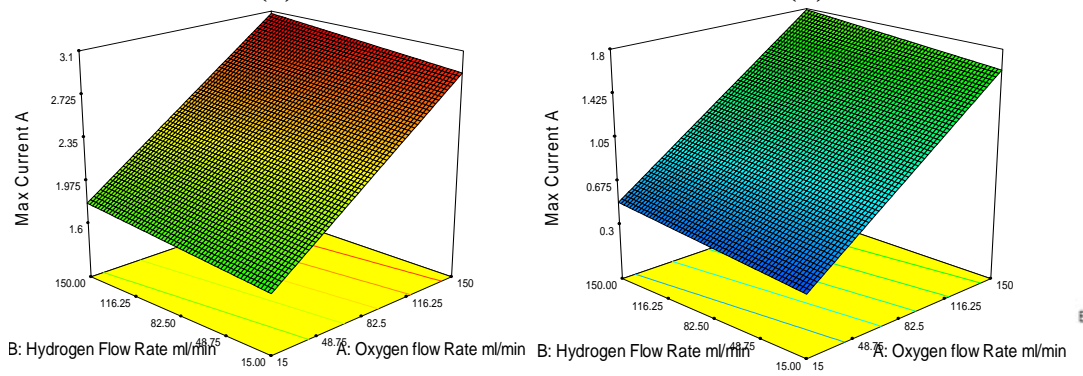

(c)

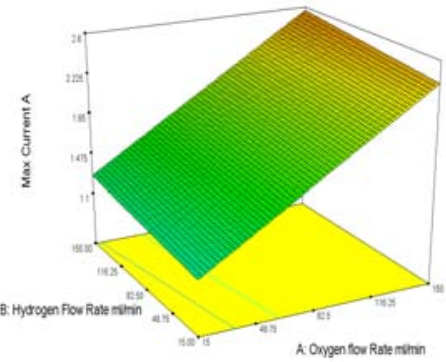

Figure 8 Maximum current achieved at maximum pressure for (a) Serpentine flow plate (b) Maze flow plate (c) Parallel flow plate

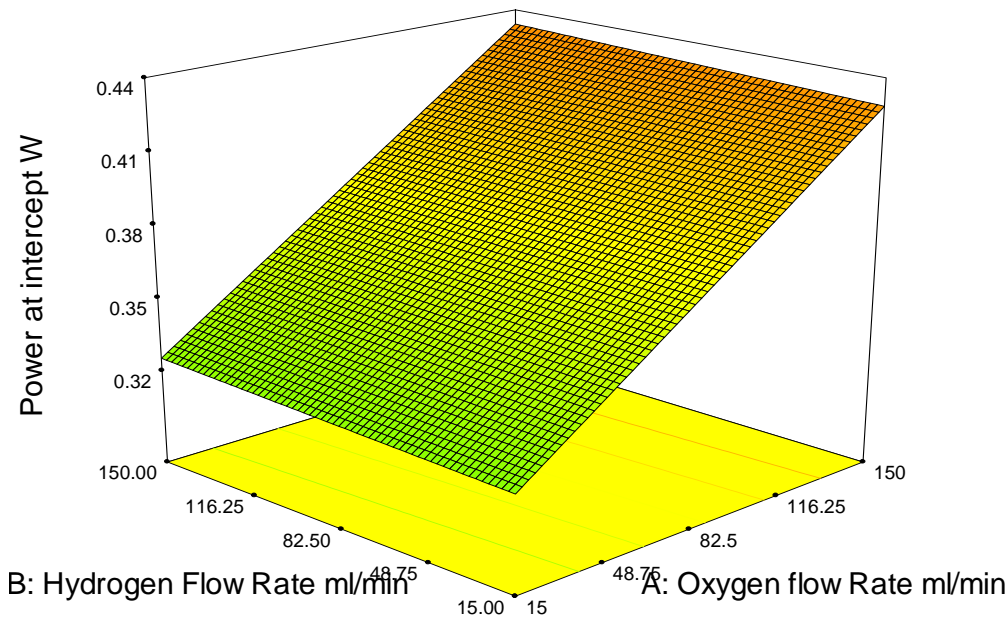

Figure 9 Serpentine flow plate power at intercept on I-V curve at medium pressure

(a)

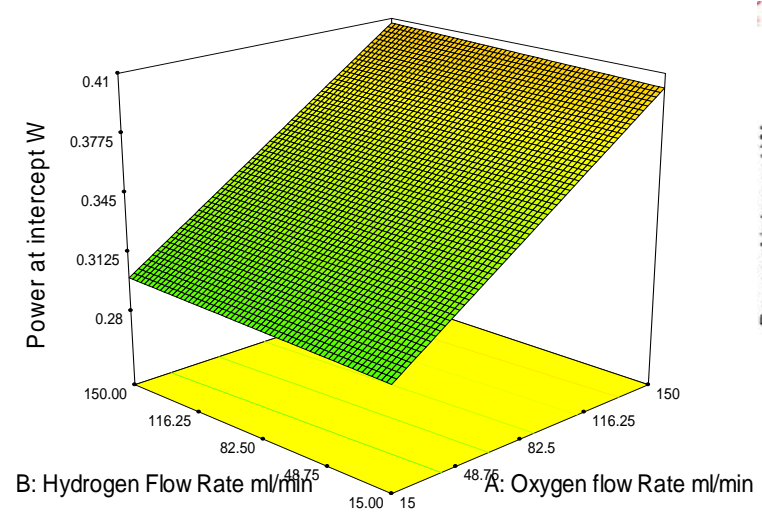

(b)

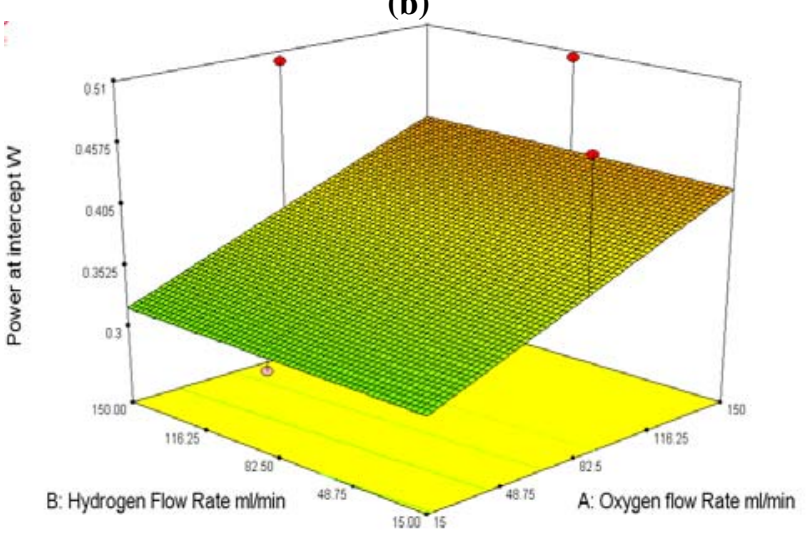

Figure 10 Parallel flow plate power at intercept on I-V curve at; medium pressure (a) maximum pressure (b) (Red points indicate experimental values above predicted DOE values) 


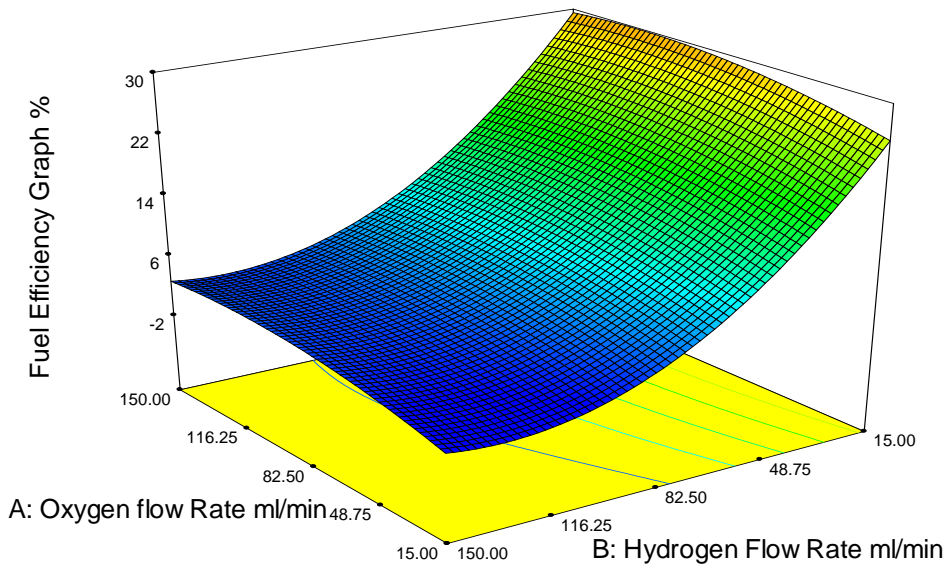

Figure 11 Serpentine flow plate fuel efficiency at medium pressure

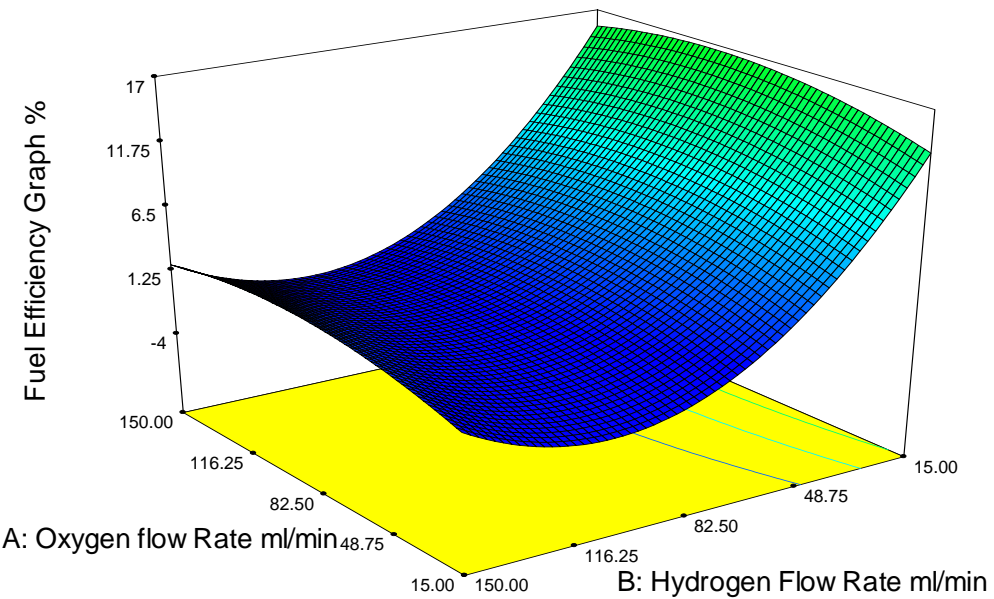

Figure 12 Maze flow plate fuel efficiency at medium pressure

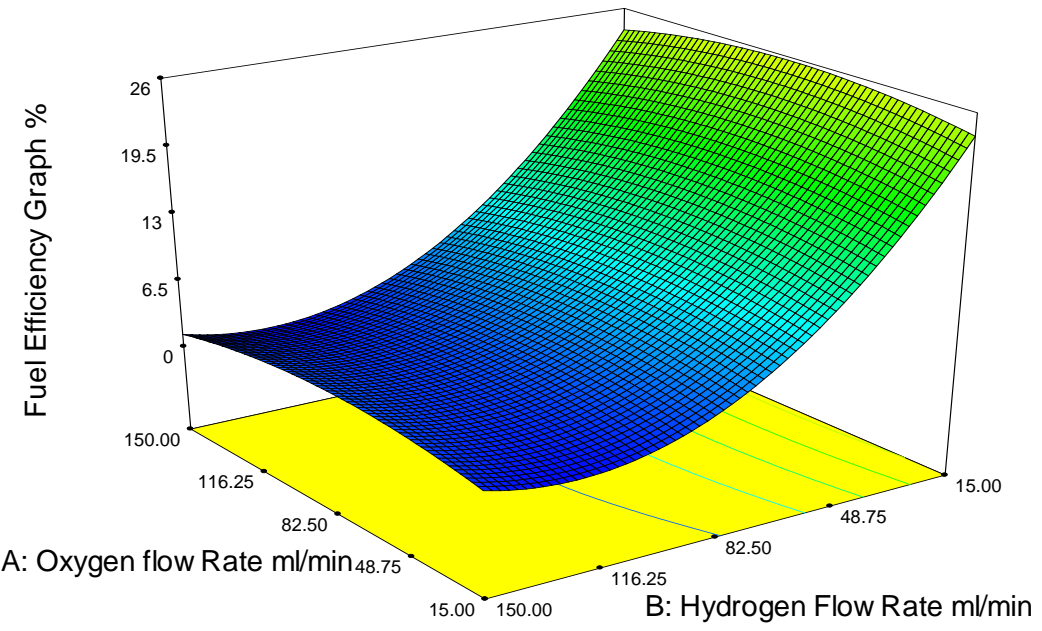

Figure 13 Parallel flow plate fuel efficiency at medium pressure 


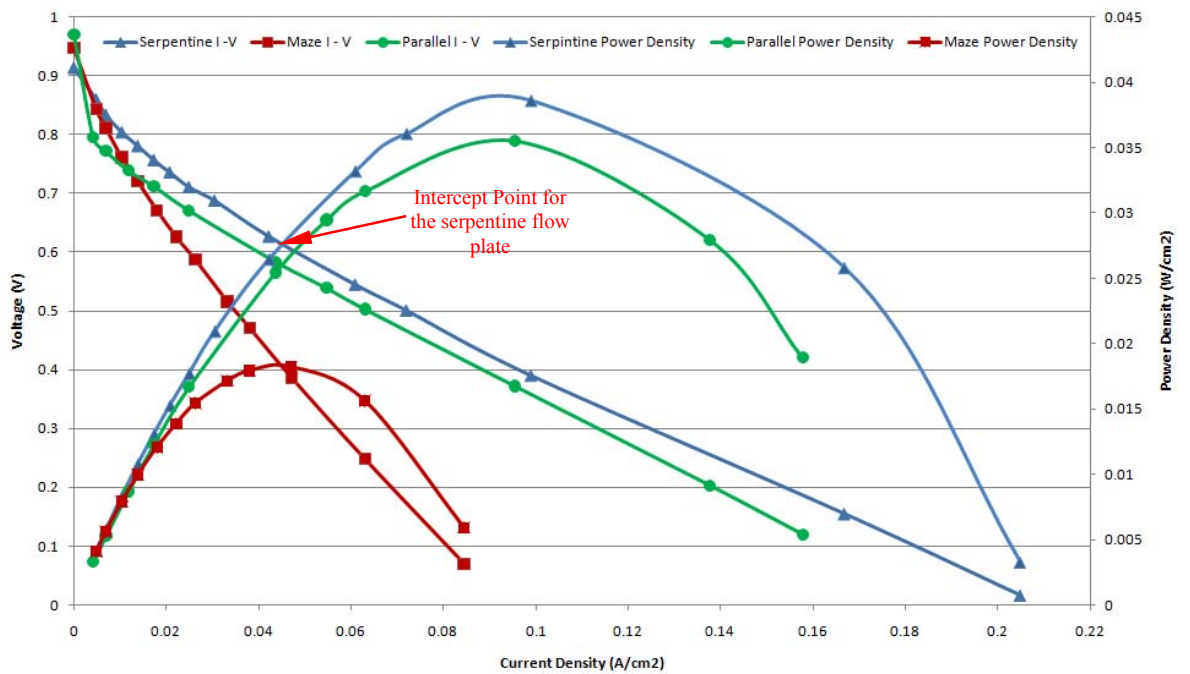

Figure 14 Polarisation curves for flow plates (Pressure 0.7bar H2 flow rate 82.5ml/min 02 flow rate $150 \mathrm{ml} / \mathrm{min})$

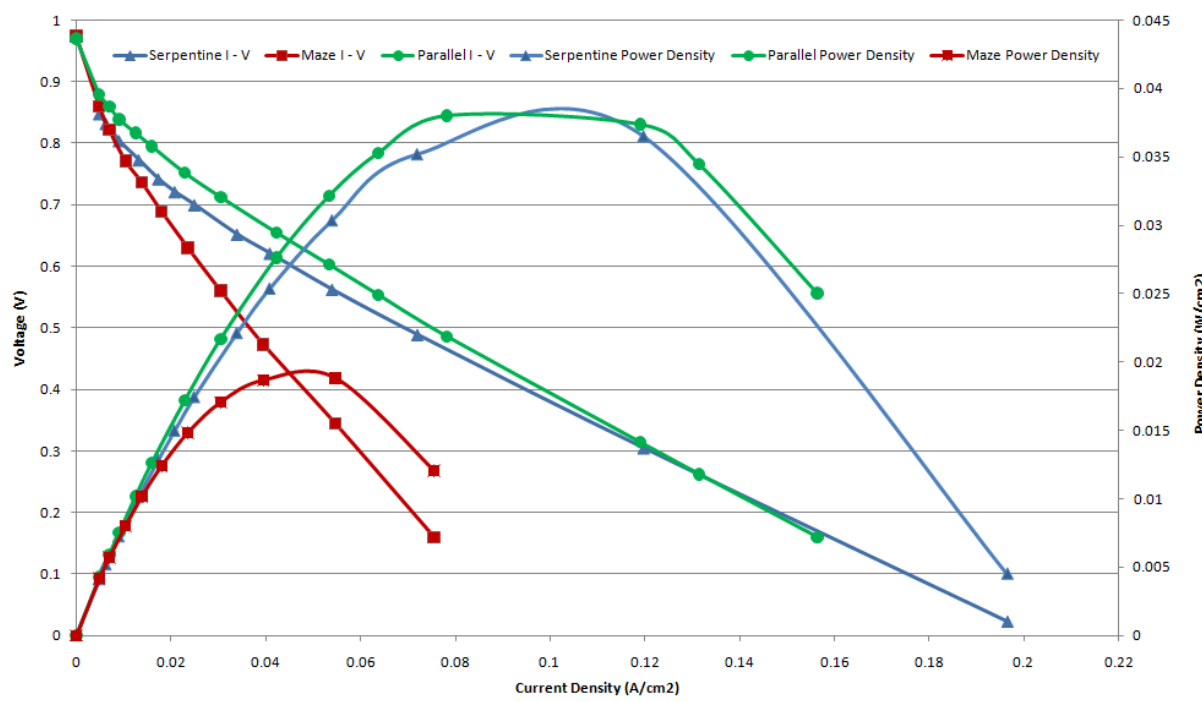

Figure 15 Polarisation curves for flow plates (Pressure 1.2bar H2 flow rate 82.5ml/min 02 flow rate $150 \mathrm{ml} / \mathrm{min})$

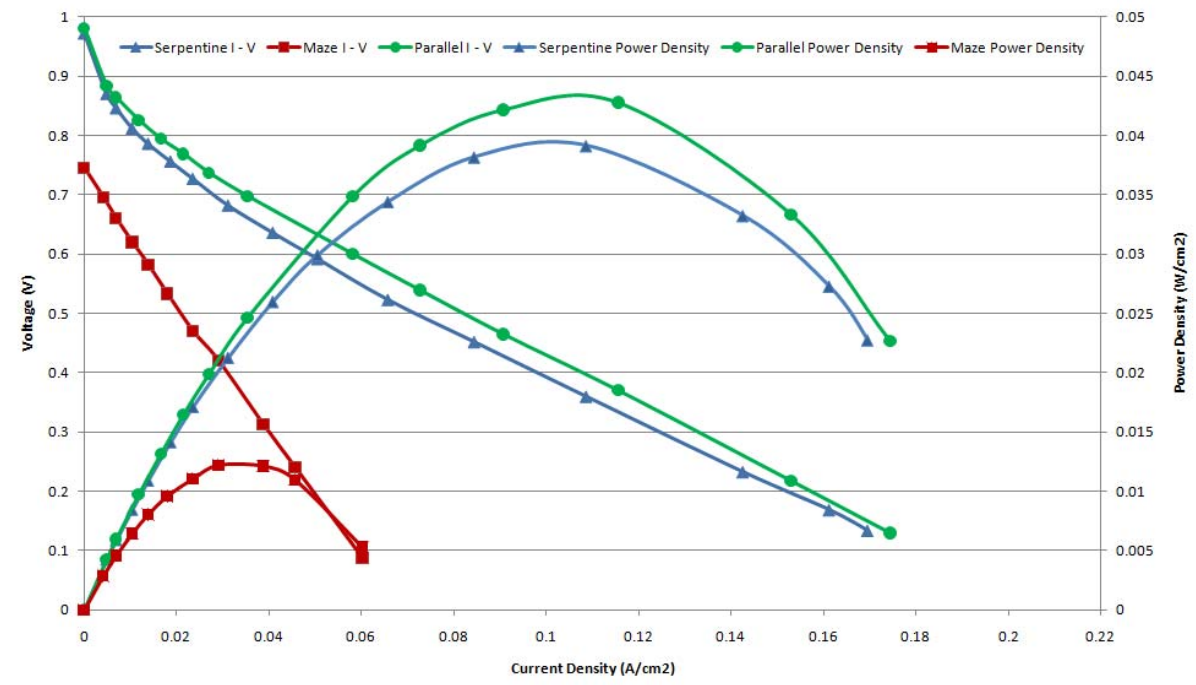

Figure 16 Polarisation curves for flow plates (Pressure 1.7bar H2 flow rate 82.5ml/min 02 flow rate $150 \mathrm{ml} / \mathrm{min})$ 